\title{
ESTROPICIOS ACADÉMICOS Y TANTEOS CRÍTICOS
}

\author{
Grínor Rojo \\ Centro de Estudios Culturales Latinoamericanos, Facultad de Filosofía y Humanidades \\ Universidad de Chile
}

Este ensayo contiene mi respuesta a la convocatoria que, estimulada por un texto del profesor José Santos Herceg, "Tiranía del paper. Imposición institucional de un tipo discursivo" ", ha hecho la Revista Chilena de Literatura para un "número especial". A aquellos de nosotros que nos hemos sentido aludidos por las palabras de Santos Herceg se nos convida, según leo en esa convocatoria, a reflexionar acerca del "lugar y la significación de las humanidades en el mundo de hoy, sobre todo pensando en nuestra propia realidad universitaria y circunstancia latinoamericana en general". En cuanto al autor del trabajo en cuestión, su tesis es que el paper constituye un género de escritura académica con características precisas y voluntad impositiva, que se ha trasladado desde el campo de las ciencias naturales y exactas al de las humanidades. Observa que los rasgos que lo definen son su condición efímera (la idea de la constante e inevitable "superación de lo antiguo por lo moderno"), la focalización en una idea aislada (su [mentirosa, a mi juicio] "modestia") y la concisión o antidigresión (el ir "al grano" sin más demora) (205-208). Se añaden a eso determinadas exigencias de estructura (básicamente, las que recomienda el "método científico" a lo Claude Bernard, 212) y de lenguaje (la erradicación de la primera persona y los tropos, entre otras exclusiones análogas y cuya meta evidente es la comunicación de lo que se quiere decir en una prosa aséptica, "objetiva”, 211). Todo ello en desmedro 
de formas del discurso que han sido de uso más o menos común en la historia de las disciplinas humanas, de las que Santos Herceg menciona varias, pero entre las cuales el "ensayo" emerge en primerísimo lugar. A lo que habría que sumar una "institucionalidad" y una cierta "organización del discurso" (200-201, se diría que la segunda como consecuencia de la primera), las que en conjunto deciden quienes son los que reciben y quienes no los premios o castigos de que se habrán hecho acreedores por su buena o su mala conducta académica: "becas", "financiamiento" o "puestos de trabajo" (201). Medidas que Santos Herceg juzga sintomáticas de "un claro intento por controlar la peligrosidad del discurso humanista, de dominar su proliferación, de organizar su incontrolabilidad" (208). Tal es, nos alecciona, el estatuto de buena parte de la investigación que en el campo de las humanidades se lleva a cabo hoy en nuestro país, la que promueven o los políticos desde los aparatos del Estado o unas instituciones de educación superior globalizadas que procuran "ponerse al día" con las tendencias actuales en el rubro, por ejemplo reproduciendo en su quehacer las directrices provenientes de la OCDE o de los acuerdos de Bolonia. Para obtener los resultados que se desean, se echa mano de dispositivos diversos, entre ellos el paper (ojalá en revistas indexadas), que es el que hegemoniza la dimensión de la escritura.

Yo estoy de acuerdo con el planteo de Santos Herceg, ni siquiera hace falta que lo diga. Creo que es acertado y oportuno, y coincido con él, aun cuando también me parece posible ensayar una profundización mayor, relativa esta vez a los orígenes, a la extensión y a los estropicios que ocasiona la enfermedad académica que ahí se diagnostica.

En lo que concierne a los orígenes, recordaré en estas páginas algo a lo que me he referido en otras circunstancias: que el afán cientificista en relación con las humanidades no tiene nada de nuevo, sino que las ha perseguido a todo lo largo de la historia de la modernidad ${ }^{2}$. Cuando en 1532 Maquiavelo le advierte al Príncipe que lo que él debe hacer, para asegurarse de que tiene a sus enemigos bajo control, es "ganar amigos, vencer o con la fuerza o con el fraude, hacerse amar y temer por los pueblos, hacerse seguir y reverenciar por los soldados, eliminar a quienes pueden o deben ofenderte, innovar el antiguo orden, ser severo y agradable, generoso y liberal, eliminar la milicia

Ver: Grínor Rojo. "Crítica de la crítica” y "De la crítica y el ensayo". Las armas de las letras. Ensayos neoarielistas. Santiago de Chile: LOM, 2008. 57-65 y 67-74, respectivamente. 
desleal, crear otra nueva, conservar las amistades de reyes y príncipes de manera que tengan que favorecerte con cortesía o atacarte con respeto"3, está dando nacimiento a la politología moderna como un conocimiento especializado sobre los mecanismos y herramientas que se aplican o pueden aplicarse en la práctica política, disasociada ésta de la ética y entendida como el logro y la mantención del poder público a no importa qué costo, y se está convirtiendo él mismo en un especialista en la materia. Eso es lo que se intensifica y "cientifiza" en el siglo XIX europeo. Un intento (fallido, estimo yo) por zanjar la polémica sin que ello fuese percibido por los afectados como un acto de capitulación desdorosa fue la propuesta de las "ciencias humanas o "ciencias del espíritu", en Dilthey, en Weber y en algunos más, cuyo propósito era prestar oído a las presiones del cientificismo pero sin desconocer las peculiaridades del trabajo que los intelectuales realizamos con la cultura. Era esa una tentativa para eludir la contradicción no por la vía de su superación sino por la de una aceptación sin desdoro de la derrota, esto es, por una sumisión honorable de uno de los términos de la dicotomía, las humanidades, en el otro, las ciencias "duras". Porque eso que estaba ocurriendo en Europa desde mediados del siglo XIX no era sino un capítulo, y el más ambicioso hasta aquel entonces, en la historia de la rearticulación moderna de nuestro conocimiento de las prácticas humanas, y en lo que a nosotros nos incumbe en particular, la de nuestro conocimiento de las prácticas culturales o simbólicas, constituidas ellas ahora en campos provistos de una cierta autonomía, o sea, premunidos cada uno con una teoría, unos métodos y unas fronteras definidas de funcionamiento.

Disciplinas diversas, como la historia, la sociología, la psicología, la lingüística y, ¡cómo no!, los estudios literarios, se subieron o se empezaron a subir, una detrás de la otra, desde alrededor de $1840^{4}$, a este carro. Y en la medida en que las ciencias exactas y las de la naturaleza tenían ya resuelto los problemas de su trámite (o por lo menos eso es lo que les pareció a quienes no era mucho lo que sabían acerca de ellas), se constituyeron en el modelo inevitable. Fue así como Comte llegó a la conclusión de que la sociología era una ciencia y nada menos que la madre de todas las ciencias, como Marx

Nicolás Maquiavelo. El príncipe, tr. Francisco Moglia. Obras selectas. Buenos Aires. Distal, 2003, p. 51.

Elijo 1840 como una fecha intermedia, ya que entre 1830 y 1842 se publica el Cours de philosophie positive, de Auguste Comte, verdadera biblia del cientificismo decimonónico. 
se adelantó a proponer una "ciencia de la historia", como Freud creyó hasta su muerte que el psicoanálisis que él había inventado era una "psicología científica" y como Saussure y los formalistas rusos hicieron la propio en el coto del lenguaje y la literatura.

Epistemológicamente, el tránsito que esos padres fundadores acabaron recorriendo, mayor en cualquier caso mientras más nos acercamos al siglo $\mathrm{XX}$, se movió desde un tipo de aproximación diacrónica o historicista, a uno sincrónico o no historicista (la historia, esa denunciadora de la fragilidad de los empeños humanos y cuestionadora por lo mismo de la naturalización de cualquiera sea el orden de cosas vigente, fue enviada al banquillo de la reserva sin sueldo) y, a poco andar, estructuralista. El mejor ejemplo de esto último lo ofrece Ferdinand de Saussure, en su Curso de lingüística general. Ese libro tiene dos y solo dos objetivos principales: sacar al objeto de la lingüística del espacio "multiforme" y "heteróclito" del lenguaje en general, a caballo éste "sobre diferentes dominios" 5 , según la colorida metáfora del propio Saussure, e instalándolo así en el que presumiblemente es el suyo propio y privativo, y restringir luego su estudio, es decir, la práctica profesional de los lingüistas, a la descripción y el análisis de "estados de lengua"6.

Discursivamente, sabemos que el rigorismo disciplinario recurrió desde la Antigüedad al "tratado" como su mejor forma de comunicación escrita. Prosa explicativa y didáctica, cuyo modelo fijó para siempre Aristóteles, que cruzó inalterado los siglos medievales (las "sumas" de Santo Tomás no son otra cosa que tratados en los que la fe es sometida a la prueba de la razón platónica y aristotélica), pero a la que en el siglo XVI le sale al paso un contendor. Eso ocurre en los Essais de Michel Montaigne, cuya primera edición es de 1580, pero que él continuó escribiendo hasta su muerte, y en los Essays de Francis Bacon, que son de 1597. Quedaba establecida a partir de aquel momento la diferencia moderna entre un pensar sistemático, sujeto a una voluntad protocientífica o científica, que es el que se vuelca en el "tratado" (y, contemporáneamente, en el "artículo" y en el "paper" que no son sino sus descendientes legítimos y de la última hora) y un pensar libre, o

Ferdinand de Saussure. Curso de lingüística general. Charles Bally y Albert Sechehaye, eds. Tr. Amado Alonso. Buenos Aires. Losada, 1967, p. 51.

"Todo lo que se llamó 'gramática general' [y que para él es la 'lingüística general" de que trata su exposición. G.R.] pertenece a la sincronía, pues solamente por los estados de lengua se establecen las diferentes relaciones que incumben a la gramática”. Ibíd., 175. 
por la libre, el del "ensayo". En el capitulo L del Libro I de su opera unica, que lleva por título "Demócrito y Heráclito", Montaigne afirmaba que él favorecía un ejercicio libre del "juicio", que el juicio él lo empleaba "en toda suerte de ocasiones" y "aprovechando cualquier argumento que me presenta la fortuna", empleo ese que de su parte requería un tratamiento del asunto que se traía entre manos "no con la máxima extensión, sino con la máxima hondura de que soy capaz". Y agrega esta linda apostilla: "las más de las veces me gusta cogerlos por algún lado insólito"7.

Es esa de Montaigne una estupenda descripción de la búsqueda demorada, circunvoluta, a lo peor caprichosa, que a nosotros nos consta que es la propia del discurso "digresivo" de las humanidades y que también es, me adelanto a sugerirlo, el motor por excelencia de su productividad. Más aún: en la página citada de Montaigne, éste les confiesa a sus lectores que él no se siente en la obligación de hablar siempre en serio, ni de aferrarse a lo ya dicho renunciando a las rectificaciones que pudieran parecerle convenientes a mitad de camino, "sin variar cuando se me antoje ni retornar a la duda y a la incertidumbre" 8 . Nada puede estar más lejos que esto de los procedimientos del paper, cuya misión en la vida, la que le han encomendado las ciencias naturales y exactas, consiste en informar acotada, precisa y objetivamente acerca de los resultados de una cierta especulación (física teórica) o de un cierto experimento (física de laboratorio).

Respecto de la extensión de la enfermedad académica cuyos síntomas "paperistas" tan bien diagnostica el profesor Santos Herceg, yo diría que es grande pero que no satura por entero el espectro de este debate. Puesto de otro modo: pienso que el campo de la cultura, la chilena, la latinoamericana y la mundial, es aún más amplio y aún más heterogéneo de lo que a él le parece y que también son amplias y heterogéneas sus formas de escritura.

La academia universitaria, aunque importante, es solo uno de los contribuyentes al todo de la producción simbólica en el mundo moderno e incluso sería aventurado contarlo entre los mayores y más poderosos. Hay más (¿y mejores?) productores de cultura no académicos que académicos y ni qué decir en América Latina: "cultura artística" (literaria, musical, de las artes visuales), "alta cultura", "cultura popular" (la tradicional y la

\footnotetext{
Michel de Montaigne. Los ensayos (según la edición de 1595 de Marie de Gournay). Jordi Bayod Brau ed. y tr. Barcelona. Acantilado, 2007, p. 437.

Ibíd.
} 
mediática), subculturas "étnicas", "genéricas", "etarias", etcétera. Hasta se coquetea últimamente con la existencia de culturas subterráneas, con lo cultural abyecto y clandestino.

Pero, como decía, es significativo que en la historia intelectual del continente no haya sido desde el sector académico sino desde el no académico desde donde surgieron algunas de las obras de máxima trascendencia. Sarmiento, Recabarren, Mariátegui están todos ellos en el origen de ideas que han influido en nuestra evolución histórica de una manera sustantiva, y todos ellos poseyeron una educación formal (académica) que fue exigua por decir lo menos. Por eso, si volvemos la mirada hacia nuestro país, yo sería partidario de que nos abstuviésemos de tomar el rábano por las hojas y de que en cambio nos abocáramos a la confección del mapa del campo cultural en el que hoy existimos, en el entendido de que ése es el dominio en que realmente habitamos, no en el dominio de la experiencia sino el de la cultura, que la cultura es el primer e insoslayable intermediario entre nosotros y el mundo. Distingo por eso, dentro de dicho mapa, ciertas "franjas" mayores de productividad, aclarando que las especies menores tienden a plegarse, de un modo u otro, con más o menos empatía (puede haber, y hay, vasos comunicantes), a alguno o algunos de los cauces más anchos. En mi opinión, las franjas de marras son tres, la primera hegemonizando ("hegemonizando", no "dominando", entiéndaseme bien) el campo y dentro de la que se debe incluir el sector más aquiescente de la producción que aquí nos ocupa en especial, la académica, y las otras dos procurando, con matices y grados de éxito que varían, oponérsele.

La franja hegemónica de la cultura contemporánea (y, dentro de la cultura contemporánea, claro está, la chilena) es la que constituyen los "expertos" con su (el horrible anglicismo se ha puesto de moda en Chile recientemente, sobre todo entre aquellos que no saben ni inglés ni español) "experticia". O sea que esta es la franja cuyo código de funcionamiento lo establecen aquellos tecnócratas y burócratas que se han propuesto adecuar sus conocimientos y habilidades al orden de cosas tal como él existe y que por lo general son individuos que circunscriben un único aspecto del mismo y a él se abocan con el fin expreso de que éste, como hubiese dicho Borges, persevere en el ser. Nunca antes habían gozado de la influencia pública que detentan (y ostentan) en la actualidad, lo que no es azaroso: la crisis capitalista mundial, la que se inaugura a fines de la década del setenta y comienzos de la del ochenta (la del ochenta la "década perdida" en América Latina), generalizó transversalmente, en vastos sectores de la población, la sensación de que la 
economía desarrollista y la política democrática habían fracasado y de que en su lugar era preciso acudir a la sabiduría de los "técnicos" y sus soluciones "científicas", específicamente las de los economistas.

En este contexto de sensación de fracaso y de desazón consiguiente es donde se instala, en gloria y majestad, la figura del intelectual experto, correlativa al necesario reforzamiento del sistema económico, social, político y cultural que ha sido el de mayor presencia en la historia moderna de Occidente, lo cual dispara fuera de la cancha, por principio y de inmediato, como si se tratara de una insensatez alucinada, cualquier pretensión de cambio. Los intelectuales expertos no están en este mundo para cambiar lo que existe, sino para mejorarlo ("planes de mejoramiento") o para proyectarlo hacia el futuro ("planes de desarrollo"). Su labor consiste, tiene que consistir, si es que atendemos a la especificidad de la posición que ellos ocupan en el campo, no en transformar sino en "innovar", esto es, en aportar a las necesidades que el país (o quien sea que les paga su salario) tiene, asumiéndose esas necesidades como las relativas al crecimiento económico predominantemente y sin que a quienes las cubren les importe ni mucho ni poco, porque ése no es un asunto de su expertise, el problema de la distribución equitativa de los beneficios, lo que en el mejor de los casos se presume que tendría que acontecer de manera automática como una consecuencia más del crecimiento. El trato que después del fin de la dictadura se ha dado en Chile a las demandas del pueblo mapuche ofrece un ejemplo a la mano. Incluso los funcionarios de gobierno menos contagiados por el ideologismo tecnocrático las han reducido al tema de la pobreza, que no cabe duda que es efectiva (los mapuche son, comprobadamente, las personas más pobres de Chile), pero remediándolo o proponiéndose remediarlo sin ningún miramiento por la historia, la identidad y las tradiciones de ese pueblo. El llamado "conflicto mapuche" es económico, cierto, pero también, muy claramente, es político y es cultural.

Una prueba más de lo que digo es el proyecto que ha anunciado el gobierno de Chile, por medio del ex ministro Pablo Longueira, para integrar la Comisión Nacional de Investigación Científica y Tecnológica (CONICYT) dentro del Ministerio de Economía ${ }^{9}$. Más que la superficialidad de un burócrata escaso

$9 \quad$ Textualmente: "el presidente me pidió que redactara el proyecto de ley para trasladar la Comisión Nacional de Investigación Científica y Tecnológica (Conicyt) al ministerio de Economía, -la semana pasada antes de partir a su gira a Rusia y Australia-, con un modelo económico que se vincule con un valor agregado y que en el fondo unamos el mundo de 
de luces, que es lo que a primera vista a muchos pudo parecernos, lo que ese proyecto revela es la convicción, por parte de quienes lo suscriben, de que la búsqueda del conocimiento o genera productos tangibles y medibles materialmente o no vale la pena.

Diré finalmente que a los intelectuales expertos se los ubica, sin perjuicio de su vocación economicista primaria, en todos los segmentos de la articulación del campo. El neoliberalismo, ha observado con lucidez Luis Cárcamo Huechante, no es una doctrina económica puramente sino que constituye también un "discurso cultural" omniinclusivo: "La tesis que sostengo es que, en este proceso, el libre mercado se constituye en un discurso cultural que, a partir de un conjunto de intervenciones retóricas e imaginarias, se despliega hegemónicamente en la sociedad" ${ }^{10}$. Por eso, los neoliberales son economistas, sociólogos, politólogos, culturólogos (en este último renglón de ordinario "gestores" culturales. El Consejo Nacional de la Cultura está lleno de ellos...) y, por supuesto, también profesores de universidad, de esos que se inclinan obedientemente ante los requerimientos que les hace el medio profesional en que se desempeñan, porque es lo que hay y debemos conformarnos con y adaptarnos a eso, y cuya multiplicación tanto preocupa a José Santos Herceg. En el plano discursivo, son los que generan los papers contra los cuales él reacciona, esos textos efímeros, focalizados a ultranza, concisos hasta la anorexia y formalizados con una rigidez ingenieril. No voy a dar nombres, porque todos los conocemos. El Ministerio de Educación, sin ir más lejos, lo dirigía hasta ayer uno de ellos.

En segundo lugar, yo distingo en el espacio cultural chileno de hoy la franja de los intelectuales "postmodernos" y hasta "postoccidentales" (dejó de lado a sabiendas a los "post" apocalípticos, a esos que especulan sobre un "sujeto posthumano" y sobre una "sociedad posthumanista", que los sobrevivientes de la máxima hecatombe están reconstruyendo from scratch, o de una sociedad en la que los cyborgs se van a hacer cargo de todo, y que anticipó Kubrick en su 2001: una odisea del espacio), los que recaban para sí una parcela dentro del mapa que ahora esbozo debido a una variedad de

la academia en Chile, el mundo de la investigación con el mundo de la empresa". Diario Financiero (11 de septiembre de 2012).

10 Luis Cárcamo-Huechante, Luis E. Tramas del mercado: imaginación económica, cultura pública y literatura en el Chile de fines del siglo veinte. Santiago de Chile. Cuarto Propio, 2007, p. 17. 
factores, entre los que se cuentan una sesgada lectura de la globalización (de preferencia, pero no exclusivamente, en lo que toca a la revolución tecnológica de la información y las comunicaciones y a sus consecuencias para la cultura del libro: la "muerte del libro" y su reemplazo por las virtudes de las tecnologías telemática, informática y cibernética, que estarían creando una nueva sociedad, la "de la información" o, más púdicamente, la "del conocimiento"), el desencanto con los socialismos (origen del así llamado "fin de las utopías") y, last but not the least, el desencanto también con las promesas del capitalismo (cuya crisis venía, como dejé dicho arriba, de atrás pero que se agudiza durante los últimos años, desde la recesión de 2008 y 2009, que afectó a Estados Unidos principalmente, hasta la actual recesión europea de 2012 y 2013).

En esta oportunidad hablo de unos intelectuales que, frente al espectáculo que les depara un sistema capitalista globalizado, el mismo que tiene al planeta en la antesala de su mutis definitivo de la escena, optan no tanto por su repudio, es decir, por el repudio de la economía que ha conducido hasta ahora el tren expreso de la historia moderna, como por el de sus fundamentos filosóficos. La acusación recae de esta manera o bien sobre la episteme fundadora de la modernidad, en el discurso de los postmodernos (embestida contra el "sujeto centrado", contra la noción de "totalidad", contra los "grandes relatos" y todo lo demás que ya conocemos), o bien sobre la episteme de la cultura occidental como un todo, en el caso de los postoccidentalistas, repudio del platonismo y reivindicación de la prístina pureza del pensamiento presocrático, cuando no echando mano de una visión se dice que "descolonizada" de los saberes alternativos, los de los pueblos indígenas, por ejemplo, a los cuales se imagina inmersos en una experiencia "pura" de la "naturaleza" de la que los europeos disfrutaron ille tempore pero que habrían perdido, lo que acaba siendo aún más colonizado que el colonialismo que se busca desechar.

Nada muy novedoso, aunque se haga con ello muchísimo ruido y no falten los ilusos que se tragan el cuento incorporándose alegremente al desfile de las insubordinaciones "post". No se dan cuenta esas buenas personas de que el antimodernismo y el antioccidentalismo son ademanes recurrentes en la historia de la cultura europea moderna, formando parte de una proclividad primitivista que estuvo disponible desde la hora cero de esa cultura como una reserva antitética con la cual oponerse desde posiciones de derecha, o sea desde eternidad de la "ley natural", a las depredaciones del "progreso sin límites", el que, como se sabe, era y es la ley de estructura del capitalismo. A ella se recurrió siempre en los momentos de crisis, primero entre los 
prerrománticos y románticos (Herder, Rousseau, Chateaubriand), después en el patrocinio que le dio Nietzsche durante la segunda mitad del siglo XIX y finalmente en la miríada de sus cultivadores contemporáneos (los serios, al menos), casi todos ellos descendientes del autor de Más allá del bien y del mal, desde Heidegger a los postestructuralistas. En términos filosóficos, me estoy refiriendo aquí a un pensamiento irracionalista, antihegeliano en principio y antiaristotélico en última instancia. Que un tipo como Gianni Vattimo, discípulo y comentarista de Nietzsche y de Heidegger y referente obligado de los postmodernos hasta hace algunos años, haya hecho pública, en 1996, en Credere di credere, su conversión a la fe católica y que por ello haya recibido la comunión piadosamente no debiera extrañarnos en semejante escenario.

En el plano del discurso escrito, tampoco debería extrañarnos que los postmodernos y los postoccidentales sean cultivadores apasionados del "fragmento". Por oposición a los cientificistas, a los escritores de papers, los postmodernos y los postoccidentales privilegian el fragmento y lo hacen porque lo cierto es que el fragmento es nada y es todo (¿no es el fragmento por definición una parte de un todo que no está visible o porque no se lo ve o porque no se lo quiere hacer visible?). El hecho es que estamos aquí frente a un programa que promueve, como su medio de comunicación favorito, la escritura de lo que es pero no es, la del "balbuceo", de lo que presumiblemente estuvo ahí "antes" del advenimiento de la terrible catástrofe del racionalismo, eso que no había aprendido a hablar aún y a lo que por lo mismo se lo supone incontaminado y exento de culpas. Como escribió Nicanor Parra en los versos con que concluye su "Soliloquio del individuo", tal vez lo mejor sería en estas condiciones volver al "valle" del principio. Freudiana, lacaniana y kristevianamente dicho, ello va a parar en el clamor por una vuelta al lenguaje "subversivo" de "lo semiótico", a la "lengua de la madre" (hasta hay un libro que editaron en 1985 Shirley Nelson Garner et al. y que se llama así. En Chile, Los vigilantes, la novela de Diamela Eltit de 1994, responde igualmente a este planteo), para confrontar con él el poder opresivo de "lo simbólico", el de la "lengua del padre". Reemergencia que donde mejor cristaliza es en el arte y la poesía, únicos lugares desde los cuales se considera posible imaginar hoy la "revolución":

en este saturado, si es que no ya cerrado, orden sociosimbólico, la poesía -más precisamente, el lenguaje poético- nos recuerda su función eterna: introducir, mediante lo simbólico, aquello que trabaja sobre él, que se mueve a través de él y que lo amenaza. La teoría del 
inconsciente busca la cosa misma que el lenguaje poético practica dentro y contra el orden social: los medios de su transformación o subversión, la precondición de su sobrevivencia y revolución ${ }^{11}$.

Desde otro lado, aunque con esa misma conciencia agónica acerca de las virtudes específicas del arte como la sola tabla de salvación disponible en un universo político y social en el que todo lo demás ha colapsado y a cuya referencia, con su "negación de la negación", el arte le da la espalda, recordemos que se había manifestado el viejo Th. W. Adorno:

Quienes contraponen el "caos" de hoy a un cosmos de valores están diciendo que ese caos ya se ha convertido en la ley de su actuación y su pensamiento. Ignoran que las normas y los criterios artísticos, si han de ser algo más que marcas identificativas de la mentalidad prescrita, no se pueden hipostasiar como algo acabado y válido más allá del ámbito de la experiencia viva. Para el arte ya no hay otras normas que las que se forman en la lógica de su propio movimiento ${ }^{12}$.

En tercer lugar, yo distingo en esta contienda la franja de los "intelectuales críticos". Reconocidos como dudadores de las verdades del sistema, además de acusados por los expertos que se han puesto a las órdenes del mismo de ser unos diletantes sin perdón de Dios y por los post (lo que no deja de ser contradictorio) de ser los sumos sacerdotes de una cultura occidental que ya no da para más, su reputación se cotiza actualmente a la baja en el mercado académico.

Con todo, yo descubro ciertos indicios de recomposición de esta perspectiva, aunque no sea más que por las continuas decepciones que provoca el trámite de las otras dos. Por ejemplo, a través del repunte de la transdisciplinariedad. El mundo contemporáneo es un mundo complejo, y cualquiera puede ver que las disciplinas tradicionales no están siendo capaces de dar razón de él con la suficiencia que se requiere y espera. Más aún: la transdisciplinariedad es la que, al hacer dialogar prácticas intelectuales de distinta índole, facilita

11 Julia Kristeva. Revolution in Poetic Language, tr. Margaret Waller. New York. Columbia University Press, 1984, p. 81.

12 Th. W. Adorno. "Sin imagen directriz. En vez de un prólogo". Sin imagen directriz. Parva aesthetica en Obra completa, 10/1. Prismas, Sin imagen directriz, tr. Jorge Navarro Pérez. Rolf Tiedemann, ed. Buenos Aires. Akal, 2008, p. 260. 
los hallazgos que reactivan y que potencialmente podrían ayudarles a salir de su atolladero a las propias disciplinas tradicionales.

No estoy diciendo nada escandalosamente transgresor, por supuesto, ya que aludo a un evento paradigmático, que ha ocurrido en el pasado y que lo más probable es que siga ocurriendo en el futuro. Cada vez que la endodisciplina se hundió en un callejón sin salida, cada vez que sus "aportes al conocimiento" se tornaron repetitivos e inanes (en los estudios literarios, los del estructuralismo a partir de la década del setenta. Barthes, que lo prohijó, se lo sacó de encima en $1967^{13}$ ), siempre fue posible recurrir a las virtudes salvíficas de la heterodisciplina o, lo que es lo mismo, a la asociación de esa búsqueda disciplinaria particular con otras menos y más lejanas, y obteniendo de semejante convergencia los mejores o los nuevos dividendos. Memorable, en este sentido, fue la reunión de la antropología con la lingüística a través del encuentro y la colaboración entre Claude Lévi-Strauss y Roman Jakobson en Nueva York en los años cincuenta del siglo XX, una reunión a la que además asistió, después de muerto, como si fuera un invitado de piedra, Sigmund Freud. Salió de ahí buena parte del aparataje que utilizamos hasta hoy en nuestros análisis literarios.

Quiero decir con esto que una de las actitudes que caracterizan al intelectual crítico es, como muy bien lo supo y lo practicó Rodó, su rechazo de la especialización "mutiladora". O sea, el pasaporte que se otorga él a sí mismo para moverse a través de y vincular los distintos ámbitos que forman el campo intelectual. Quiero decir a fortiori que ese pasaporte no ha caducado y que tampoco constituye un acto de diletantismo hacer uso de él, como suele proclamar una opinión oficial que, como bien decía Adorno, "suele pensar con las orejas" ${ }^{14}$. Hoy no solo es legítima sino urgente una mirada teórica que en el campo de las humanidades abandone de un lado la monotemática servicialidad de la expertise y del otro la falsa rebeldía de los hacedores de fragmentos. Y eso asimismo en un doble sentido: como una mirada que se atreve a abarcar ambiciosamente espacios variados de la experiencia humana, en primer término, de forma tal que con esa mirada se reamarren los hilos que conectan a distintos modelos de comprensión de la realidad, proponiendo

13 Aludo a "La muerte del autor", reconocidamente el primero de sus ensayos postestructuralistas.

14 Adorno. "Crítica de la cultura y sociedad", en Crítica de la cultura y sociedad I. Prismas, 9. 
(proponiendo, no imponiendo) al cabo la imagen de un todo nuevo, pero coherente y con sentido, y en segundo, como una práctica simbólica que se muestre en condiciones de recuperar la unión entre la teoría y la praxis y de convertirse, por lo tanto, en un instrumento de cambio genuino.

Para hacer todo eso, claro está que los papers de los expertos sirven de bien poco y que menos todavía es lo que sirven los fragmentos de los postmodernos y los postoccidentales. En cambio, sirve el ensayo, que, si hemos de recurrir a la brillante definición de Martín Cerda, es la "escritura del tanteo" ${ }^{15}$. Por oposición al experto, que con sus papers informa metódica y secamente sobre los resultados de una investigación, el intelectual crítico es ése que "tantea", que inicia el tratamiento de su tema "por algún lado insólito" (Montaigne dixit), que luego se desplaza con morosidad y regusto, que actúa en fin con la certidumbre de que el lenguaje que emplea no es transparente y que no pocas veces extrae de ahí precisamente, de esa su no transparencia, del surplus "connotativo" del discurso que él mismo habrá puesto en movimiento, lo mejor de su cosecha.

Puede que con la excepción de quienes realizan actividades sistemáticas de apoyo, cuya utilidad yo no solo no desconozco sino que agradezco, como son las del filólogo o las del investigador de archivos, pero de los cuales tampoco se puede decir que lo que hacen sea ciencia dura, ¿será una exageración introducir aquí la tesis de que el del intelectual crítico es, más que cualquiera otro, el discurso de las humanidades? ¿qué si el paper es un medio de expresión apropiado para las ciencias naturales y exactas, no tiene por qué serlo y no lo es para las humanidades? ¿Y que así un intelectual crítico que escribe papers deviene tan contradictorio como un científico que da a conocer sus findings en la forma del ensayo?

Porque el intelectual crítico no es un comunicador de "verdades" sino un introductor de "preguntas". Éstas, asegura Beatriz Sarlo, no son las del "hacer sino del cómo armar una perspectiva para ver" ${ }^{16}$. Tanteamos, es decir "ensayamos" (del latín exagium, "acto de pesar algo", según leo en

15 "Tantear es un modo de orientarse hacia lo desconocido e indescubierto". Martín Cerda. La palabra quebrada. Ensayo sobre el ensayo. Valparaíso. Ediciones Universitarias de Valparaíso, 1982, p. 19.

16 Beatriz Sarlo. Escenas de la vida postmoderna, Intelectuales, arte y cultura en la Argentina. Buenos Aires. Espasa Calpe/Ariel, 1994, p. 10. 
Corominas ${ }^{17}$, y "ensayar" con la significación de "probar", de "hacer la prueba", que por lo menos cuatro de las ocho acepciones del Diccionario de la Real Academia reproducen ${ }^{18}$ ), para aflojar estrecheces, para abrir compuertas, para que la imaginación teórica fluya libre y creadora. Alguna vez sostuve, y lo reproduzco aquí, que el ensayo era, en sus más acabadas expresiones, en Montaigne, en Goethe, en Michelet, en el Barthes que se ha aliviado de la mochila estructuralista y, entre nosotros, en José Martí, en Baldomero Sanín Cano, en Pedro Henríquez Ureña, en José Carlos Mariátegui, en Antonio Candido o en Ángel Rama, un texto fronterizo entre el utile y el dulce horaciano o, más precisamente, entre la razón y el arte. En efecto, si lo pensamos desde el punto de vista del trivium medieval, el que conjugaba la lógica con la gramática y la retórica, tendríamos que concluir que su lenguaje, que su "gramática", establece un equilibrio entre los territorios que el trivium consideraba que eran privativos del lógico y del retórico. Equidistante por igual del texto explicativo que del literario, el ensayo finge ser siempre uno de ellos pero escapándose hacia el otro.

Los estropicios: yo estoy convencido de que estamos viviendo en un mundo injusto y, lo que no es menos grave, peligroso. Estoy convencido también de que en este mundo, en el que las cuentas las están pagando los justos por los pecadores, el capitalismo en crisis ha puesto en marcha una estrategia de reacumulación (en la jerga de los economistas, un "ajuste estructural") para así salvarse por el camino de un relanzamiento de sus tendencias naturales: la sobreexplotación del hombre y la naturaleza, el consumo frenético y la guerra. Y estoy convencido, por último, de que los intelectuales expertos son los turiferarios de esa estrategia, quiéranlo o no, y que los intelectuales postmodernos y postoccidentales son sus cómplices, quiéranlo o no igualmente. Por lo que una refutación fundada de los discursos "científicos" que se guardan en los papers de los humanistas cientificistas y de los falsos saberes que frívolamente recogen los fragmentos de los "post" no tiene nada de superflua, pues nos permite salirles al paso a equívocos que son onerosos, porque suelen entontecer e inutilizar la cultura contemporánea de izquierda, la chilena, la latinoamericana y la mundial. Me he acostumbrado

17 Joan Corominas. Breve diccionario etimológico de la lengua castellana, $3^{\mathrm{a}}$ ed. Madrid. Gredos, 1994, p. 236.

18 Real Academia Española. Diccionario de la lengua española, $21^{\mathrm{a}}$ ed. Tomo I. Madrid. Real Academia Española, 1992, p. 845. 
a repetir por y para esto una oposición en la que Georg Lukács insiste en las páginas finales del prefacio autocrítico del 62 a su Teoría de la novela. Por muy bien intencionada que sea, piensa él que es vana de toda vanidad "la concepción del mundo que apunta a una fusión entre una ética 'de izquierda' y una epistemología 'de derecha' (ontología, etc.)” o, lo que es igual, que es preciso abrir bien los ojos cuando lo que se nos está vendiendo es "una ética de izquierda, orientada hacia una revolución radical", pero que "se confunde con una exégesis tradicional-convencional de la realidad". Entre los intelectuales alemanes de su tiempo, cuenta Lukács, la confusión llegó al colmo cuando ellos intentaron "movilizar a Nietzsche y hasta a Bismark como fuerzas progresistas contra la reacción fascista" 19 .

Son trampas tan viejas como la modernidad misma y en las que el intelectual crítico contemporáneo no tiene por qué caer de nuevo. En cambio, yo considero que éste debiera reasumir el papel que fue el suyo a lo largo de los últimos quinientos años de la historia de Occidente, porque su inteligencia rebelde y su discurso del tanteo nos hacen falta todavía, porque en la guerra de posiciones que se libra contemporáneamente en el terreno de la cultura ese pensamiento y esos textos no tienen sustituto. Solo con su ayuda se podrá restablecer la prioridad de unos valores que no ponen el incremento del dinero en el primer lugar de su agenda sino el incremento de la vida y que son y serán siempre los valores de los desposeídos frente a los disvalores de los dueños y los beneficiarios del poder.

19 Georg Lukács. The Theory of the Novel. A histórico-philosophical essay on the forms of great literature. Trad. Anna Bostock. Cambridge, Massachusetts: The MIT Press, 1975, pp. 21-22. 